(C) Danone Research 2012. The online version of this article is published within an Open Access environment subject to the conditions of the Creative Commons Attribution-NonCommercial-ShareAlike licence $<$ http://creativecommons.org/licenses/by-nc-sa/3.0/ $>$. The written permission of Cambridge University Press must be obtained for commercial re-use.

\title{
Hydration biomarkers in free-living adults with different levels of habitual fluid consumption
}

\author{
Erica Perrier ${ }^{1 *}$, Sébastien Vergne ${ }^{1}$, Alexis Klein ${ }^{1}$, Marie Poupin $^{1}$, Pascale Rondeau ${ }^{1}$, Laurent Le Bellego ${ }^{1}$, \\ Lawrence E. Armstrong ${ }^{2}$, Florian Lang ${ }^{3}$, Jodi Stookey ${ }^{4}$ and Ivan Tack ${ }^{5}$ \\ ${ }^{1}$ Danone Research, RD 128, 91767 Palaiseau, France \\ ${ }^{2}$ Human Performance Laboratory, University of Connecticut, Unit 1110, Storrs, CT 06269-1110, USA \\ ${ }^{3}$ Institute of Physiology, University of Tübingen, Gmelinstrasse 5, D-72076 Tübingen, Germany \\ ${ }^{4}$ Children's Hospital Oakland Research Institute, 5700 Martin Luther King Jr Way, Oakland, CA 94609, USA \\ ${ }^{5}$ Department of Clinical Physiology, Toulouse Hospital and University, 31059 Toulouse, France
}

(Submitted 28 March 2012 - Final revision received 6 July 2012 - Accepted 14 July 2012 - First published online 31 August 2012)

\begin{abstract}
Little is known about the impact of habitual fluid intake on physiology. Specifically, biomarkers of hydration status and body water regulation have not been adequately explored in adults who consume different fluid volumes in everyday conditions, without prolonged exercise or environmental exposure. The purpose of the present study was to compare adults with habitually different fluid intakes with respect to biomarkers implicated in the assessment of hydration status, the regulation of total body water and the risk of kidney pathologies. In the present cross-sectional study, seventy-one adults (thirty-two men, thirty-nine women, age 25-40 years) were classified according to daily fluid intake: thirty-nine low drinkers (LD; $\leq 1.2$ litres/d) and thirty-two high drinkers (HD; 2-4litres/d). During four consecutive days, urinary parameters (first morning urine (FMU) on day 1 and subsequent $24 \mathrm{~h}$ urine (24hU) collections), blood parameters, and food and beverage intake were assessed. ANOVA and non-parametric comparisons revealed significant differences between the LD and HD groups in $24 \mathrm{hU}$ volume (1.0 (SE 0.1) v. $2 \cdot 4$ (SE 0.1) litres), specific gravity (median 1.023 v. 1.010), osmolality (767 (SE 27 ) $v$. $371(\mathrm{SE} 33) \mathrm{mOsm} / \mathrm{kg}$ ) and colour (3.1 (SE 0.2) $v \cdot 1 \cdot 8(\mathrm{SE} 0 \cdot 2)$ ). Similarly, in the FMU, the LD group produced a smaller amount of more concentrated urine. Plasma cortisol, creatinine and arginine vasopressin concentrations were significantly higher among the LD. Plasma osmolality was similar between the groups, suggesting physiological adaptations to preserve plasma osmolality despite low fluid intake. The long-term impact of adaptations to preserve plasma osmolality must be examined, particularly in the context of renal health.
\end{abstract}

Key words: Hydration biomarkers: Fluid intake: Urine: Osmolality

Water is the most abundant compound in humans and is essential for all main functions of the body ${ }^{(1)}$. Water loss occurs constantly through the lungs, skin, kidneys and gastrointestinal tract, and has an adverse impact on physical ${ }^{(2,3)}$ and cognitive ${ }^{(4,5)}$ performance if uncompensated. Thus, the intake of sufficient water to compensate for daily losses is crucial. Total water intake comes from multiple sources, including drinking-water and other beverages and moisture content in food, and water is also produced within the body via oxidative metabolism. However, because drinking-water and other beverages constitute approximately $80 \%$ of total water intake in European and American diets ${ }^{(6)}$, adequate fluid consumption is therefore critical for maintaining essential body functions.

There is no consensus about how much total water, or, more specifically, drinking-water and other beverages (hereafter referred to as fluid) an individual should consume. The lack of consistent recommendations reflects uncertainty about how to monitor or measure the hydration process in the general population. Many methods for measuring hydration status have been proposed, and detailed reviews have explored their strengths and weaknesses ${ }^{(7-9)}$. Overall, however, no single method appears to be adequate for all situations ${ }^{(7)}$. When water losses are rapid or substantial, such as with exercise or environmental exposure, an increase in plasma osmolality or urine specific gravity (USG) can signal dehydration ${ }^{(10)}$; moreover, a decrease in body mass is a validated technique to estimate acute water loss and establish adequate replacement fluid intake, particularly among athletes ${ }^{(11)}$. However, for the general population, for whom water losses are less pronounced, and whose water balance is thus influenced

Abbreviations: 24hU, $24 \mathrm{~h}$ urine; AVP, arginine vasopressin; CRI, Crystallization Risk Index; FMU, first morning urine; HD, high drinker; LD, low drinker; NHANES, National Health and Nutrition Examination Survey; USG, urine specific gravity.

*Corresponding author: E. Perrier, fax +33 1693576 93, email erica.perrier@danone.com 
largely by fluid intake, it remains unclear whether there is meaningful or biologically significant variability in these same physiological parameters.

At the country level, recommendations for total water intake (fluid and food) are based in large part on epidemiological analyses of observed intakes from national food surveys. For example, the Institute of Medicine guidelines for adequate intake of total water for the USA and Canada (3.7 and 2.7 litres/d for adult men and women, respectively) were established based on median total water intake from US survey data, under the assumption that in large population studies, fluid intake will be greater than or equal to body water needs ${ }^{(12)}$. There are efforts to take physiological parameters into consideration. The European Food Safety Authority bases its adult total water intake recommendations (2.5 and 2.0 litres/d for men and women, respectively) on both observed intakes and relative to a 'desirable' urine osmolarity of $500 \mathrm{mOsm} / \mathrm{l}^{(6)}$, based on the renal solute load derived from dietary surveys from multiple European countries. However, the European Food Safety Authority report concedes that solute load from dietary records varies widely between countries; moreover, the calculation of water volume necessary to achieve the desired urine osmolality is theoretical. In order to establish recommendations for total water intake supported by physiological indicators, the impact of habitual fluid intake practices on hydration biomarkers and water balance must be described.

In France, total fluid intake from drinking-water and other beverages ranges widely, from as low as 0.5 litres/d in the first decile to greater than 3.0 litres/d in the highest decile, with some individuals reporting consumption of greater than $4 \cdot 0$ litres daily ${ }^{(13,14)}$. Moreover, the distribution of total fluid consumption by French adults can be stratified into three relatively equal tertiles, with the bottom third of adults consuming less than 1.2 litres/d, the middle third consuming between $1 \cdot 2$ and $2 \cdot 0$ litres/d and the top third consuming greater than $2 \cdot 0$ litres/d. Currently, it is not known whether individuals who habitually consume high volumes are physiologically similar to those who drink lower volumes of fluid.

The objective of the present study was to assess the impact of habitually different total fluid intake behaviours (low consumption $<1.2$ litres $/ \mathrm{d} v$. high consumption $>2 \cdot 0$ litres $/ \mathrm{d}$ ) on multiple biomarkers of hydration status in free-living conditions. Specifically, we were interested in exploring urine and blood biomarkers implicated in (1) the traditional assessment of hydration status, (2) the regulation of total body water by the kidneys and (3) the risk of kidney pathologies. To our knowledge, no study has previously investigated physiological differences between people voluntarily exhibiting different fluid consumption levels in free-living conditions.

\section{Experimental methods}

\section{Subjects}

The study enrolled healthy Caucasian French men and women, aged 25-40 years, with a BMI between 18.5 and $29.5 \mathrm{~kg} / \mathrm{m}^{2}$ and with habitual fluid consumption (drinking-water plus other beverages) falling into either the bottom or top thirds of the French fluid intake distribution. Initial inclusion criteria included the ability to stay at home, abstain from strenuous physical activity for the study duration ( $4 \mathrm{~d}$ ), access the Internet and live within a maximum of $30 \mathrm{~min}$ from the investigating centre. Exclusion criteria included use of medication likely to interfere with metabolism, such as hypotensive or diuretic treatment, history of gastrointestinal or metabolic disease (such as diabetes mellitus); renal, hepatic or cardiac failure, smoking more than fifteen cigarettes per $\mathrm{d}$; or consumption of more than two (women) or more than three (men) standard servings of alcohol per weekday (where one standard serving represents $250 \mathrm{ml}$ beer, $100 \mathrm{ml}$ wine or $30 \mathrm{ml}$ of spirits). Participants completed a total of six clinic visits (Fig. 1). After an initial eligibility screening (V0), potentially eligible subjects completed a clinical examination and received instructions on to use an electronic diary questionnaire (e-diary; MXS-Epidemio), described in detail below, to estimate usual fluid consumption over three consecutive weekdays. Subjects then returned to the clinic for an inclusion visit (V1), where their e-diary was used to identify individuals whose daily fluid consumption was consistent with either the low drinker (LD; $\leq 1.2$ litres/d per $1.73 \mathrm{~m}^{2}$ of body surface area) or high drinker (HD; $2 \cdot 0-4.0$ litres/d per $1.73 \mathrm{~m}^{2}$ body surface area) groups.

A total of 274 subjects were screened between August and December 2009. Of these, ninety-seven individuals $(35.4 \%)$ satisfied the initial screening criteria and reported daily fluid consumption that consistently classified them as either LD ( $n$ 48) or HD ( $n$ 49). The study was conducted according to the guidelines laid down in the Declaration of Helsinki and all procedures involving human subjects were approved by the Comite de Protection des Personnes of Ile de France XI. Written informed consent was obtained from all subjects. The final analysis sample includes thirtynine LD and thirty-two HD participants who complied with the protocol and completed all the measures required during the study period.

\section{Experimental design}

The study was a comparative study of two non-randomised groups (LD and HD). Enrolled subjects were asked to follow their usual daily activities and food and fluid consumption habits. Study participants had four clinic visits (evaluation visits; V2-V5) within 3 weeks of completing the screening process. Evaluation visits were scheduled to run from Tuesday to Friday to avoid the weekend when dietary habits could be different from those on weekdays. Starting on the Monday before the evaluation visits, subjects again used the e-diary to record daily food and fluid intake. The following morning, subjects collected their first morning urine (FMU) at home, and delivered it to the clinic during their first evaluation visit (V2). Study participants continued to complete the food and fluid e-diary and collected $24 \mathrm{~h}$ urine (24hU) specimens over the next $3 \mathrm{~d}$, and reported to the clinic each morning (V3-V5) to deliver their $24 \mathrm{hU}$ collections. A fasting blood sample was drawn during each morning visit (V2-V5). 


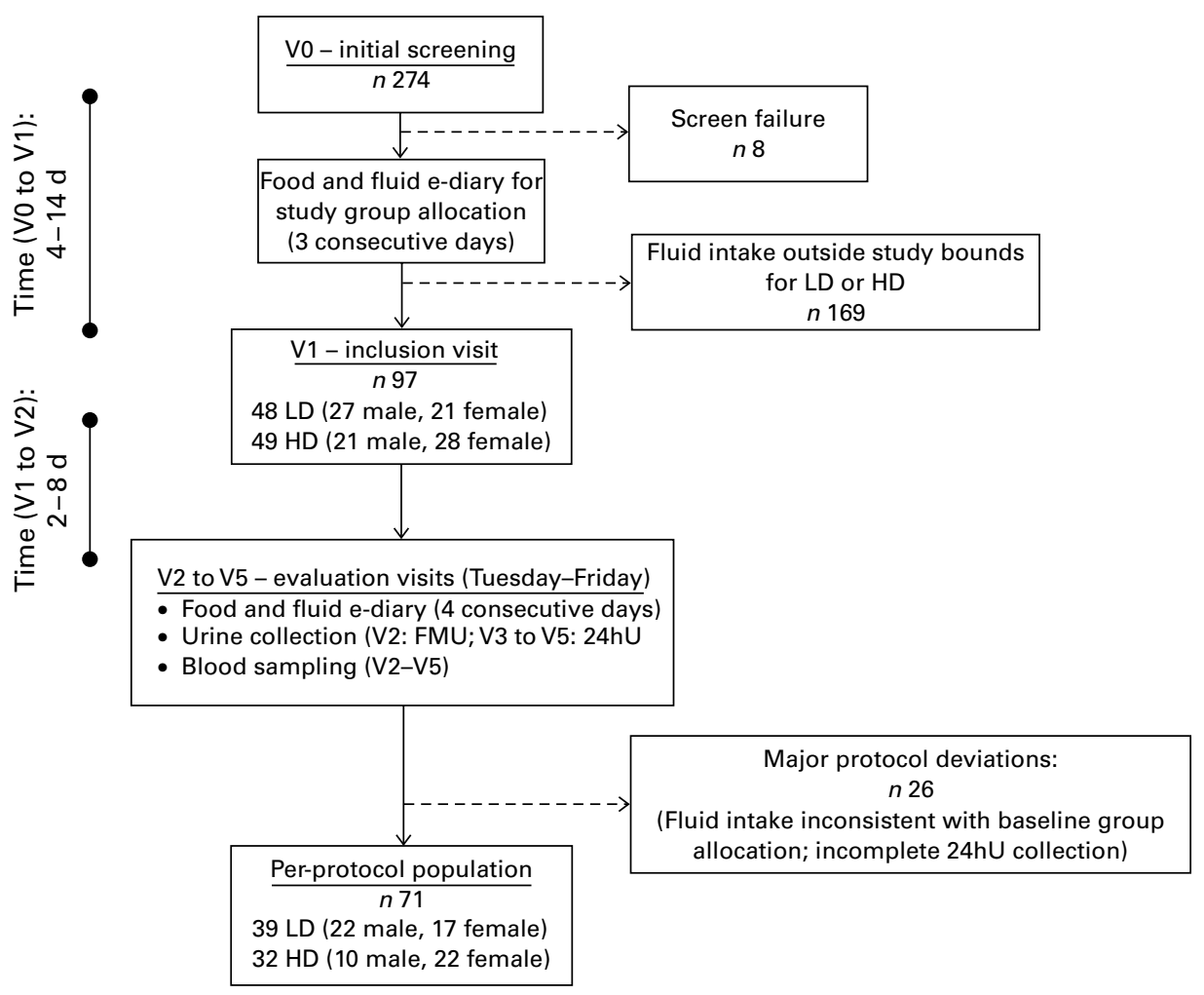

Fig. 1. Schematic of subject recruitment, group allocation and experimental phase. $24 \mathrm{hU}, 24 \mathrm{~h}$ urine; LD, low drinker; HD, high drinker; FMU, first morning urine.

The central laboratory remained blinded to the status (LD or HD) of the participants.

\section{Food and fluid intake diary}

The e-diary is an electronic food questionnaire that was specifically developed for epidemiological studies of food and fluid intake in France. For every entry, subjects recorded the meal type (breakfast, lunch, dinner or snack), time of day, and characteristics of all food and beverage items consumed. Food item selections were made using a database of component pictures based on the French Data Centre on Food Quality (Centre d'Information sur la Qualité des Aliments; CIQUAL) table ${ }^{(15)}$, a reference databank of the nutritional composition of more than 1300 generic foods. A unique and helpful aspect of this tool was that, for a selected food item, the software automatically suggested other foods normally associated with it in the French diet. To finalise the record, subjects were prompted to record the quantity of each of the selected components, using a list of proposed portions or directly in terms of weight or volume. The software computes daily intake totals for macro- and micronutrients, trace elements and water content of foods and beverages. Beverages were selected from an extensive list and were grouped for descriptive purposes into seven classes: drinking-water (tap and bottled); flavoured water; dairy beverages (including drinkable yogurt and fermented milk beverages); hot beverages (coffee and tea); sweetened still beverages (e.g. fruit juices, bottled iced tea); carbonated sweetened beverages (e.g. colas); alcohol. Total water intake was calculated from the moisture content in food and the total water volume in beverages, including alcohol.

\section{Urine and blood biomarkers}

A broad selection of biomarkers in the urine (FMU and 24hU) and blood was assessed, with specific biomarkers presented in the Results section (Tables 1-3). Broadly, we were interested in the following: (1) markers that have routinely been used in the determination of hydration status, such as urine and plasma osmolality, USG and urine colour ${ }^{(16,17)}$; (2) hormones implicated in the regulation of body water via the kidneys, such as arginine vasopressin (AVP) and aldosterone; (3) indicators of risk for kidney pathologies, such as concentrations of solutes that are known to be associated with kidney stones $^{(18)}$. These three categories were of interest because of their potential to be directly influenced by daily fluid intake. The majority of analyses were performed directly by the central laboratory (ExcelBio; Laboratoire Thébault) with specific analyses (osmolality, aldosterone, AVP and renin) performed by specialised laboratories (SGS Aster and Biomnis).

\section{Urine collection procedures}

The FMU collected for V2 was collected separately from the three subsequent $24 \mathrm{hU}$ collections. All urine was stored at $4^{\circ} \mathrm{C}$ and biological components were analysed daily on the fresh samples. During each evaluation visit, total urine mass was determined to the nearest $1 \mathrm{~g}$ and a sample was retained for analysis. Urine osmolality was measured via freezing point 
Table 1. Characteristics of the first morning urine in the low and high drinkers

(Adjusted mean values with their standard errors; medians and quartiles)

\begin{tabular}{|c|c|c|c|c|c|c|c|c|c|c|}
\hline & \multicolumn{4}{|c|}{ Low drinkers ( $n$ 39) } & \multicolumn{4}{|c|}{ High drinkers ( $n$ 32) } & \multicolumn{2}{|c|}{$P$} \\
\hline & $\begin{array}{l}\text { Adjusted } \\
\text { mean }\end{array}$ & SE & Median & Q1-Q3 & $\begin{array}{l}\text { Adjusted } \\
\text { mean }\end{array}$ & SE & Median & Q1-Q3 & $\begin{array}{l}\text { Group } \\
\text { effect }\end{array}$ & $\begin{array}{l}\text { Sex } \\
\text { effect }\end{array}$ \\
\hline \multicolumn{11}{|c|}{ Normal distribution: mixed ANOVA linear model } \\
\hline Volume (litres) & 0.233 & 0.020 & & & 0.301 & 0.024 & & & 0.035 & NS \\
\hline USG & 1.021 & 0.001 & & & 1.016 & 0.001 & & & 0.020 & NS \\
\hline Osmolality (mOsm/kg) & 794 & 40 & & & 590 & 47 & & & 0.001 & NS \\
\hline $\mathrm{Na}(\mathrm{mmol} / \mathrm{l})$ & $116 \cdot 8$ & 6.5 & & & $76 \cdot 8$ & $7 \cdot 7$ & & & $<0.001$ & NS \\
\hline $\mathrm{K}(\mathrm{mmol} / \mathrm{l})$ & $42 \cdot 6$ & 3.5 & & & 31.7 & $4 \cdot 1$ & & & 0.046 & NS \\
\hline Phosphate $(\mathrm{mmol} / \mathrm{l})$ & $37 \cdot 0$ & $2 \cdot 6$ & & & $27 \cdot 6$ & $3 \cdot 0$ & & & 0.022 & NS \\
\hline Creatinine $(\mathrm{mmol} / \mathrm{l})$ & 17.5 & 1.0 & & & $12 \cdot 5$ & 1.2 & & & 0.003 & NS \\
\hline Uric acid $(\mathrm{mmol} / \mathrm{l})$ & 3.4 & 0.2 & & & 2.5 & $0 . \overline{3}$ & & & 0.007 & NS \\
\hline Urea $(\mathrm{mmol} / \mathrm{l})$ & 432.6 & 24.6 & & & 332.0 & $29 \cdot 0$ & & & 0.010 & NS \\
\hline $\mathrm{Mg}(\mathrm{mmol} / \mathrm{l})$ & 3.8 & 0.4 & & & 3.7 & 0.4 & & & NS & NS \\
\hline $\mathrm{pH}$ & $6 \cdot 0$ & 0.1 & & & 5.9 & 0.1 & & & NS & NS \\
\hline Tiselius CRI & 1.31 & 0.16 & & & 1.42 & 0.20 & & & NS & NS \\
\hline \multicolumn{11}{|c|}{ Normality assumption rejected: non-parametric Wilcoxon rank-sum test } \\
\hline Citrate $(\mu \mathrm{mol} / \mathrm{l})$ & & & 1918 & $1081-2953$ & & & 1304 & $709-2067$ & 0.026 & \\
\hline $\mathrm{Ca}(\mathrm{mmol} / \mathrm{l})$ & & & 4.3 & $2 \cdot 6-6 \cdot 4$ & & & 2.7 & $1 \cdot 7-4 \cdot 8$ & 0.051 & \\
\hline Colour ${ }^{(20,21)}$ & & & 3.0 & $2 \cdot 0-4 \cdot 0$ & & & 2.5 & $2 \cdot 0-3 \cdot 0$ & NS & \\
\hline Cortisol (nmol/l) & & & 46.9 & $24 \cdot 8-71 \cdot 7$ & & & 35.9 & $19 \cdot 3-52 \cdot 4$ & NS & \\
\hline Aldosterone $(\mathrm{nmol} / \mathrm{l})$ & & & 27 & $13-41$ & & & 23 & $11-38$ & NS & \\
\hline Oxalate $(\mu \mathrm{mol} / \mathrm{l})$ & & & 266 & $177-432$ & & & 261 & $183-438$ & NS & \\
\hline
\end{tabular}

USG, urine specific gravity; CRI, Crystallization Risk Index.

osmometry (Messtechnik). USG was determined using a pen refractometer (ATAGO Company). Urine volume was calculated from urine mass and USG. Urine biochemistry assays were performed daily, with the following exceptions: cortisol, aldosterone, citrate and oxalate, which were stored at $-20^{\circ} \mathrm{C}$ and batch processed. From the biochemical urine analyses, the Tiselius Crystallization Risk Index (CRI) was calculated $^{(18)}$. The Tiselius CRI is useful in evaluating the risk of recurrent kidney stone formation, and takes into account the total volume of urine produced as well as the excretion of solute elements that increase ( $\mathrm{Ca}$ and oxalate) or decrease ( $\mathrm{Mg}$ and citrate) the risk of calcium oxalate stone formation ${ }^{(19)}$.

\section{Blood collection procedures}

During each evaluation visit, a $40 \mathrm{ml}$ fasting-state blood sample was drawn. Aliquots for plasma osmolality were measured using a fresh sample via freezing point osmometry (Messtechnik). A sample for measuring serum cortisol and creatinine was collected in a $5 \mathrm{ml}$ dry tube. Samples for plasma haematocrit, AVP, renin and aldosterone were collected in EDTA tubes. Assays were performed immediately on fresh samples, with the exception of renin, aldosterone and AVP, which were frozen at $-20^{\circ} \mathrm{C}$ and batch processed weekly. After processing, all samples were stored at $-80^{\circ} \mathrm{C}$.

\section{Statistical analysis}

The Statistical Analysis Systems software package version 9.2 (SAS Institute) was used for analyses. An assumption of normal distribution was evaluated for each variable. A distribution was considered as approximately normal if the values of skewness and kurtosis fell within the interval $[-1,+1]$. In the case of normal distribution, comparison between the groups was done using ANOVA including group, sex and group $\times$ sex interaction as factors when measurement was done at only one time point (i.e. FMU) When there were repeated measurements, ANOVA for repeated measures, including group, sex, visit and associated interactions as factors, was performed. For ANOVA comparisons, results are reported as means with their standard errors for LD and HD, and group means were adjusted for sex as a covariate. If the normality assumption was rejected, a Wilcoxon non-parametric rank-sum test was used, and results are reported using medians and interquartile ranges (Q1-Q3). All statistical tests were two-sided with an $\alpha$ risk equal to $0 \cdot 05$.

\section{Results}

\section{Per-protocol subject characteristics}

Overall, twenty-six subjects presented with at least one major deviation and were excluded from the per-protocol population. These major deviations mostly fell into two categories: first, fluid consumption during the evaluation period that was not consistent with consumption at baseline ( $n$ 20), therefore invalidating the participant's assignment to the LD or HD group; second, excessive inter-day variation $(\geq 20 \%)$ or in $24 \mathrm{~h}$ creatinine clearance ( $n$ 5), suggesting that at least one of the $24 \mathrm{hU}$ collections was incomplete. The per-protocol population consisted of seventy-one subjects, thirty-nine LD (56\% male; age 31.3 (SD 4.5) years) and thirty-two HD (31\% male; age $32 \cdot 1$ (SD $4 \cdot 2$ ) years), with the sex difference between the groups approaching statistical significance (Fisher's exact test: $P=0 \cdot 055)$. 
Table 2. Characteristics of $24 \mathrm{~h}$ urine in the low and high drinkers

(Adjusted mean values with their standard errors; medians and quartiles)

\begin{tabular}{|c|c|c|c|c|c|c|c|c|c|c|}
\hline & \multicolumn{4}{|c|}{ Low drinkers ( $n$ 39) } & \multicolumn{4}{|c|}{ High drinkers ( $n$ 32) } & \multicolumn{2}{|l|}{$P$} \\
\hline & Adjusted mean & SE & Median & Q1-Q3 & Adjusted mean & SE & Median & Q1-Q3 & Group effect & Sex effect \\
\hline \multicolumn{11}{|c|}{ Normal distribution: mixed ANOVA linear model } \\
\hline Volume (litres) & 1.011 & 0.081 & & & $2 \cdot 387$ & 0.097 & & & $<0.001$ & $0.002^{*}$ \\
\hline Colour & $3 \cdot 1$ & 0.2 & & & 1.8 & 0.2 & & & $<0.001$ & NS \\
\hline Osmolality (mOsm/kg) & 767 & 27 & & & 371 & 33 & & & $<0.001$ & NS \\
\hline $\mathrm{Na}(\mathrm{mmol} / 24 \mathrm{~h})$ & $110 \cdot 1$ & $6 \cdot 2$ & & & $140 \cdot 1$ & 7.5 & & & 0.003 & $<0.001^{*}$ \\
\hline $\mathrm{K}(\mathrm{mmol} / 24 \mathrm{~h})$ & $55 \cdot 9$ & $2 \cdot 8$ & & & 64.0 & 3.4 & & & NS & $<0.001^{*}$ \\
\hline $\mathrm{Mg}(\mathrm{mmol} / 24 \mathrm{~h})$ & $3 \cdot 0$ & $0 \cdot 1$ & & & $3 \cdot 3$ & 0.2 & & & NS & $<0.001^{*}$ \\
\hline $\mathrm{Ca}(\mathrm{mmol} / 24 \mathrm{~h})$ & 4.5 & 0.3 & & & 4.7 & 0.4 & & & NS & $<0.001^{*}$ \\
\hline Phosphate (mmol/24h) & $25 \cdot 4$ & $1 \cdot 1$ & & & 24.4 & 1.3 & & & NS & $<0.001^{*}$ \\
\hline Creatinine (mmol/24h) & $13 \cdot 6$ & 0.4 & & & 12.5 & 0.5 & & & NS & $<0.001^{*}$ \\
\hline $\mathrm{CrCl}(\mathrm{ml} / \mathrm{min})$ & $116 \cdot 8$ & 3.7 & & & $116 \cdot 0$ & 4.4 & & & NS & $<0.001^{*}$ \\
\hline Uric acid (mmol/24h) & 3.1 & 0.1 & & & 3.3 & 0.2 & & & NS & $<0.001^{*}$ \\
\hline Urea $(\mathrm{mmol} / 24 \mathrm{~h})$ & $347 \cdot 3$ & $16 \cdot 4$ & & & 357.8 & $19 \cdot 6$ & & & NS & $<0.001^{*}$ \\
\hline $\mathrm{pH}$ & $6 \cdot 2$ & $0 \cdot 1$ & & & $6 \cdot 2$ & 0.1 & & & NS & NS \\
\hline \multicolumn{11}{|c|}{ Normality assumption rejected: non-parametric Wilcoxon rank-sum test } \\
\hline USG & & & 1.023 & $1.018-1.027$ & & & 1.010 & $1.008-1.011$ & $<0.001$ (all visits) & \\
\hline Cortisol (nmol/24h) & & & 74 & $47-104$ & & & 103 & $85-126$ & $<0.05(\mathrm{~V} 4, \mathrm{~V} 5)$ & \\
\hline Oxalate $(\mu \mathrm{mol} / 24 \mathrm{~h})$ & & & 266 & $188-388$ & & & 482 & $266-666$ & $<0.05$ (all visits) & \\
\hline Tiselius CRI & & & 1.3 & $1.1-1.9$ & & & 0.8 & $0.5-1.4$ & $<0.05$ (all visits) & \\
\hline Aldosterone (nmol/24h) & & & 33 & $22-49$ & & & 30 & $24-49$ & NS & \\
\hline Citrate $(\mu \mathrm{mol} / 24 \mathrm{~h})$ & & & 2342 & $1253-2688$ & & & 2069 & $1700-3349$ & NS & \\
\hline
\end{tabular}

$\mathrm{CrCl}$, creatinine clearance; USG, urine specific gravity; CRI, Crystallization Risk Index.

* $P$ values were significantly higher than those for females. 
Table 3. Characteristics of fasting blood samples in the low and high drinkers

(Adjusted mean values with their standard errors; medians and quartiles)

\begin{tabular}{|c|c|c|c|c|c|c|c|c|c|c|}
\hline & \multicolumn{4}{|c|}{ Low drinkers (n 39) } & \multicolumn{4}{|c|}{ High drinkers (n 32) } & \multicolumn{2}{|l|}{$P$} \\
\hline & $\begin{array}{l}\text { Adjusted } \\
\text { mean }\end{array}$ & SE & Median & Q1-Q3 & $\begin{array}{l}\text { Adjusted } \\
\text { mean }\end{array}$ & SE & Median & Q1-Q3 & Group effect & $\begin{array}{c}\text { Sex } \\
\text { effect }\end{array}$ \\
\hline \multicolumn{11}{|c|}{ Normal distribution: mixed ANOVA linear model } \\
\hline Cortisol (nmol/l) & $545 \cdot 0$ & $21 \cdot 6$ & & & $459 \cdot 2$ & $25 \cdot 5$ & & & 0.012 & $<0.001 \dagger$ \\
\hline Creatinine $(\mu \mathrm{mol} / \mathrm{l})$ & $80 \cdot 1$ & 1.4 & & & 74.5 & $1 \cdot 7$ & & & 0.013 & $<0.001^{*}$ \\
\hline Haematocrit & 0.412 & 0.003 & & & 0.408 & 0.004 & & & NS & $<0.001^{*}$ \\
\hline \multicolumn{11}{|c|}{ Normality assumption rejected: non-parametric Wilcoxon rank-sum test } \\
\hline $\operatorname{AVP}(\mathrm{pmol} / \mathrm{l})$ & & & 2.4 & $1.8-3.4$ & & & 1.5 & $1 \cdot 1-1.9$ & $<0.001$ (all visits) & \\
\hline $\operatorname{Renin}(\mathrm{pg} / \mathrm{ml})$ & & & $18 \cdot 5$ & $13 \cdot 1-33 \cdot 7$ & & & $20 \cdot 9$ & $17 \cdot 3-27 \cdot 2$ & NS & \\
\hline Aldosterone (pmol/l) & & & 406 & $277-604$ & & & 477 & $296-699$ & NS & \\
\hline Posm (mOsm/kg) & & & 289 & $284-294$ & & & 288 & $284-293$ & NS & \\
\hline
\end{tabular}

AVP, arginine vasopressin; Posm, plasma osmolality.

${ }^{*} P$ values in males were significantly higher than those in females.

$\dagger P$ values in females were significantly higher than those in males.

\section{Total water intake}

Drinking-water and other beverages (fluid intake). The results of repeated-measures ANOVA revealed significant between-group differences in daily fluid intake during the study period, with LD consuming 0.74 (SD 0.37 ) litres and HD consuming $2 \cdot 70$ (SD $0 \cdot 40)$ litres $(P<0 \cdot 001)$. The effect of sex was also significant $(P=0 \cdot 002)$, with males in both groups consuming more fluid than their female counterparts. Drinking-water (tap and bottled) appeared to be the major contributor to fluid intake, representing $65 \%$ of all beverages among the HD and $47.5 \%$ among the LD (Fig. 2).

Water from food. The amount of water from food was largely similar between the groups, with Wilcoxon ranksum tests revealing no significant between-group differences during V3, V4 and V5. During V5, the median (Q1-Q3) volume of water obtained from food was 0.55 litres $(0.41-0.81)$ in the LD group, and 0.68 litres $(0.51-0.88)$ in the HD group.

\section{First morning urine}

ANOVA revealed significant between-group differences for the following indices of hydration status in the FMU: volume $(P=0.035)$; specific gravity $(P=0.020)$; osmolality $(P=0.001)$. Among the LD, the FMU volume was lower, and USG and osmolality were higher than among the HD (Table 1). FMU concentrations of $\mathrm{Na}, \mathrm{K}$, phosphate, creatinine, uric acid, urea and citrate were also significantly higher in the LD. Cortisol, aldosterone, urine colour, pH, and the Tiselius CRI were similar in both groups.

\section{$24 h$ urine}

In the $24 \mathrm{hU}$ samples, significant between-group differences were found for urine volume, colour, osmolality and USG $(P<0 \cdot 001)$. Subjects in the LD group excreted significantly less urine than those in the HD group over each $24 \mathrm{~h}$ period ( $1.0 v .2 .4$ litres), and their urine was more concentrated, as reflected by a darker colour (3.1 $v .1 \cdot 8)$, higher osmolality $(767 v .371 \mathrm{mOsm} / \mathrm{kg})$ and higher specific gravity (1.023v.1.010)
(Table 2). The distribution of $24 \mathrm{hU}$ osmolality values among the LD and HD is shown in Fig. 3. There were also significant sex differences, with males producing a greater urine volume than females $(P=0 \cdot 002)$, and therefore excreting a significantly greater quantity of solute over each $24 \mathrm{~h}$ period $(\mathrm{Na}, \mathrm{K}, \mathrm{Mg}, \mathrm{Ca}$, phosphate, creatinine, uric acid and urea; all $P<0 \cdot 001)$.

\section{Blood variables}

Plasma concentrations of cortisol, creatinine and AVP were all higher in the LD group $(P<0 \cdot 001$; Table 3$)$. There were no between-group differences in haematocrit, active renin, aldosterone or plasma osmolality. In both groups, males exhibited higher values than females for cortisol, creatinine and haematocrit $(P<0 \cdot 001)$.

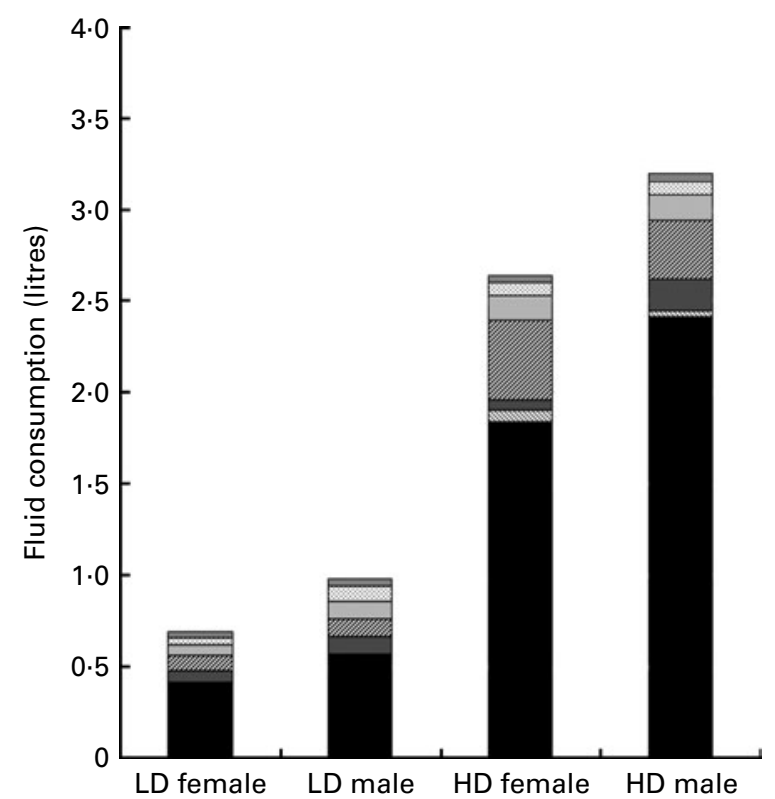

Fig. 2. Mean daily total fluid consumption classified by beverage class, for female and male low drinkers (LD) and high drinkers (HD). $\mathrm{B}$, Alcoholic beverages; 圈, carbonated beverages; $\square$, sweetened still beverages; 四, hot beverages; $\square$, milk and milk products; $\mathbb{\mathbb { }}$, flavoured water; $\boldsymbol{\square}$, water. 


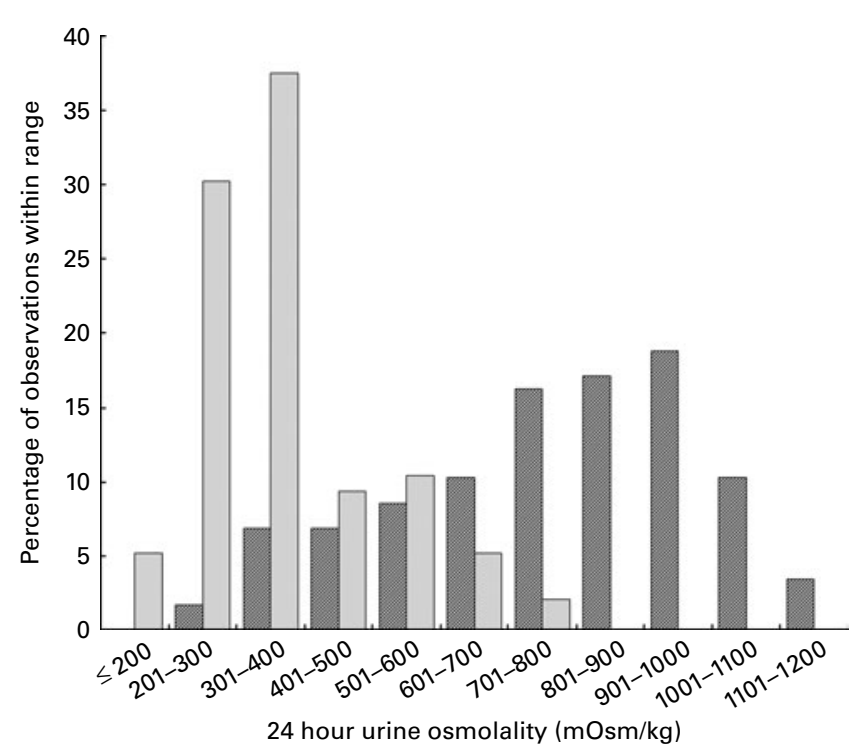

Fig. 3. Distribution of $24 \mathrm{~h}$ urine osmolality measurements among the low drinkers (四) and high drinkers ( $\square$ ).

\section{Discussion}

The purpose of the present study was to compare a broad range of biomarkers in individuals with habitually different fluid intakes, to determine whether the differences in fluid intake that occur in daily life are associated with biologically significant variability. The results of the present study reveal several important differences between habitually LD and HD. First, urine biomarkers (volume, osmolality, specific gravity and colour) distinguish fluid intake habits between habitually LD and HD in free-living conditions. In contrast, despite a difference of more than 2 litres/d of total water intake, plasma osmolality was not different between the groups. Second, the proportion of total water intake obtained from beverages is markedly different between the groups, and is not in line with assumptions used by authorities to establish water intake recommendations. Third, the present findings suggest that individuals who habitually consume low fluid volumes show evidence of physiological adaptations to conserve total body water and maintain normal plasma osmolality, including increased expression of AVP and higher plasma cortisol. Moreover, the physiological adaptations to conserve total body water, which include a low urine volume, may have longterm implications for kidney health.

Differences in total water intake between the groups came mostly from drinking-water and beverages, while the contribution from water in food was similar (approximately 0.6 litres) in both groups. This contradicts assumptions used in both European and US recommendations for total water intake that all individuals obtain about $20 \%$ of their total water from food ${ }^{(6)}$. The present results confirm this percentage in the HD, where water in food represented on average $23 \%$ of total fluid intake; however, in the LD, almost half (47\%) of total fluid intake was obtained from food. This finding suggests that the percentage of total water attributed to food may not be consistent across the fluid intake spectrum.
Moreover, this challenges the establishment of total water recommendations that assume water from food as a percentage of total water, and makes a case for the establishment of a fluid intake recommendation specific to drinking-water and other beverages.

The average total water intake reported by the LD barely satisfied even conservative physiological estimates of minimum daily water loss. Using a composite of previously published data, the European Food Safety Authority estimates the physiological minimum necessary daily water loss via urine, stool, skin and lungs to be 1.3-1.5 litres, exclusive of sweating ${ }^{(6)}$, while the Institute of Medicine estimates minimum daily water loss to be between 1.3 and 3.45 litres $^{(12)}$. However, despite the substantial differences in fluid consumption between the groups, there was no difference in plasma osmolality, with mean values of 289 and $288 \mathrm{mOsm} / \mathrm{kg}$ in the LD and HD, respectively. This suggests that in the absence of rapid and substantial water loss due to fluid restriction, exercise or environmental exposure, powerful physiological responses efficiently regulate plasma osmolality within an extremely narrow range. It therefore appears necessary to draw a clear distinction between the validity of plasma osmolality as a marker of acute and substantial body water loss, and its usefulness in differentiating between the LD and HD in less extreme environments. Cheuvront et al. ${ }^{(20)}$ recently reported that plasma osmolality was the only body fluid marker in which a single measured value could accurately diagnose acute dehydration. However, the dehydrated state was achieved by performing long-duration exercise in hot conditions, followed by an overnight stabilisation period. Moreover, in some instances of hypohydration ${ }^{(17,21)}$, plasma and serum osmolality do not track closely with acute changes in body weight or urinary indices. It has been suggested that because of its importance to cardiovascular function, plasma volume is defended in situations of mild hypohydration and thus plasma variables may not be affected until substantial body water has been lost ${ }^{(9)}$. This is in agreement with intake data from the Third National Health and Nutrition Examination Survey (NHANES III), showing that serum osmolality was maintained at a constant level over a wide range of water intake deciles ${ }^{(12)}$. The aggregate of the present results, in combination with the NHANES data, supports the conclusion that plasma osmolality is not sensitive to variation in ad libitum fluid intake in free-living conditions.

The similarity in plasma osmolality values observed between the LD and HD suggests that physiological compromises took place in order to preserve plasma osmolality and volume. This is supported by significantly higher urine concentration as well as the increased expression of AVP in the LD group. In both first morning and $24 \mathrm{hU}$ samples, the LD had significantly lower urine volumes coupled with higher osmolality and specific gravity. In addition, plasma AVP, cortisol and creatinine were significantly higher in the LD. The increase in plasma AVP observed in the LD group is consistent with its main function, to increase water permeability of the collecting duct cells in the kidney, facilitating water reabsorption and resulting in more concentrated urine ${ }^{(22)}$. Furthermore, AVP stimulates the downstream release 
of adrenocorticotropic hormone, resulting in the increased expression of glucocorticoids, including cortisol $^{(23,24)}$. Increased serum cortisol has already been associated with hypohydration in strenuous conditions ${ }^{(25,26)}$, and the present findings support this observation. However, to our knowledge, this is the first study to document an elevation in plasma cortisol in the LD, in the absence of acute dehydration. Moreover, a surprising finding was that cortisol excretion in $24 \mathrm{hU}$ was higher in the HD group. Because cortisol and other glucocorticoid metabolites exit the body via urine, higher cortisol excretion in the HD may suggest that fluid intake plays a role in the rate of metabolism and the elimination of cortisol. This observation is intriguing, but preliminary; future studies are necessary to further explore the relationship between fluid intake and cortisol elimination. Together, the elevated plasma concentrations of AVP and cortisol under normal life conditions may indicate that the LD engage physiological mechanisms to maintain total body water content. As cortisol is a major stress hormone ${ }^{(23)}$, it appears appropriate to hypothesise that chronic limited fluid intake in the LD may be associated with a mild but chronic stress response.

The physiological adaptations in the LD that allow for the preservation of plasma volume are achieved at a potential cost to the renal-urinary system. In the present study, $24 \mathrm{hU}$ osmolality in the LD group was essentially unchanged compared with the first morning sample. In comparison, $24 \mathrm{hU}$ osmolality in the HD was lowered by roughly one-third relative to the corresponding FMU sample. The distribution of $24 \mathrm{hU}$ osmolality values, shown in Fig. 2, illustrates striking differences between the LD and HD groups. For instance, two-thirds of the $24 \mathrm{hU}$ samples in the HD group had osmolality values between 200 and $400 \mathrm{mOsm} / \mathrm{kg}$. In contrast, twothirds of the $24 \mathrm{hU}$ samples in the LD group were above $700 \mathrm{mOsm} / \mathrm{kg}$, with nearly one-third above $900 \mathrm{mOsm} / \mathrm{kg}$. Considering the kidney's maximal urine concentrating capacity, estimated to be between 900 and $1400 \mathrm{mOsm} / \mathrm{kg}^{(6,27)}$, it appears that in at least a subset of the LD, the kidney may be approaching its maximal urine concentrating capacity over consecutive $24 \mathrm{~h}$ periods. At present, the literature documenting chronically elevated urine osmolality and kidney function is scarce. However, fluid intake and urine output are closely linked to urine osmolality ${ }^{(28)}$, and recent papers have reported links between intake, urine volume and kidney function. Clark et $a l .{ }^{(29)}$ compared the annual decline in estimated glomerular filtration rate among a large cohort of adults, and found that the annual rate of estimated glomerular filtration rate decline was inversely proportional to urine production, with the fastest rate observed in individuals whose urine volumes were less than 1 litre/d. This corresponds to roughly half of the LD in our sample, as twenty-one of the thirty-nine subjects had $24 \mathrm{hU}$ volumes of less than 1 litre. Moreover, a second recent study ${ }^{(30)}$ has reported that high fluid intakes were associated with a significantly lower risk of chronic kidney disease. In the context of available data on French drinking habits $^{(13,14,31,32)}$, these studies have suggested that ad libitum habitual drinking habits may not sufficiently protect against the increased risk of chronic kidney disease for a substantial slice of the French population.

Finally, the increase in plasma creatinine concentration observed in the LD may result from either decreased renal creatinine clearance or increased creatinine production. Upon investigation of $24 \mathrm{hU}$ variables, neither daily urinary creatinine clearance nor creatinine excretion was different between the groups. Given that the LD group included more male participants, and that males have higher plasma creatinine concentrations, it would appear that the simplest explanation for the difference between the LD and HD may have been the sex composition of the groups. However, this explanation may be too simplistic, given that the sex composition of the LD and HD groups was accounted for in the analysis. There also exists a plausible theoretical mechanistic explanation for increased plasma creatinine in the LD. Creatinine is continually produced from the degradation of creatine and phosphocreatine ${ }^{(33,34)}$. Cellular creatine uptake is accomplished by a creatine transporter (SLC6A8) that is stimulated by Serum/glucocorticoid-regulated kinase 1 (SGK1) $^{(35)}$. Because

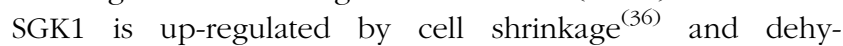
dration $^{(37,38)}$, the LD may have higher rates of cellular creatine uptake (and thus higher rates of breakdown). Thus, the increased plasma creatinine concentration is at the very least consistent with the low fluid intake observed in the LD group.

The present study was designed to compare habitually LD and HD, which limits the interpretation of the findings to those individuals who are reasonably consistent in their daily fluid intake volume. It is not clear how a variable fluid intake, with high intake volumes on some days and low volumes on others, would have an impact on the biomarkers of hydration reported in the results. It is likely that individuals who transition from a low to high drinking volume, or vice versa, would experience a change in hydration biomarkers; however, the latency of these changes, as well as identifying which biomarkers are the most responsive to a change in fluid intake, still needs to be explored. However, in terms of applicability to real-world conditions, the present study's main strength is that individuals continued to eat and drink as they normally would, including a mix of drinking-water and other beverage categories. Moreover, these findings have potentially important health implications: despite ad libitum access to water and other beverages in free-living conditions, a proportion of the French population consumes barely enough fluid to compensate even minimum estimated daily losses. Acutely, the higher plasma concentrations of AVP in habitual LD suggest that the kidney is being relied upon to a greater degree to conserve water. Lower fluid intake and urine volumes are also associated with an increased risk of chronic kidney disease. This suggests that long-term kidney function depends, at least in part, upon how hard the kidney must work to maintain water balance.

\section{Conclusion}

The results of the present study suggest the possibility of differentiating $\mathrm{LD}$ and $\mathrm{HD}$ on the basis of urine characteristics, particularly $24 \mathrm{~h}$ volume, osmolality and specific gravity. 
These measures could be particularly useful in establishing recommended daily intakes for water that are based on physiological indicators of adequate hydration status rather than on median consumption data. While plasma osmolality was not different between the groups, examination of urinary and plasma hormone parameters suggests that the tight control of plasma osmolality comes at a cost, namely increased circulating cortisol and AVP and increased urine osmolality in the LD. The long-term impacts of these adaptations are not yet certain, but recent evidence points to a link between insufficient fluid intake and urine volumes and the risk of chronic kidney disease. Therefore, we propose that future determinations of adequate total water intake take into account the ability of the body to maintain both plasma and urine osmolality at moderate levels. Moreover, because water from food may not represent a consistent percentage of total water intake, future guidelines should specify intake requirements for water from fluids, independent of the contribution of moisture from food.

\section{Acknowledgements}

This study was supported by Danone Research. E. P., A. K., M. P., P. R. and L. L. B. are employees of Danone Research. L. E. A., F. L., J. S. and I. T. are occasional consultants for Danone Research. S. V., A. K., L. L. B., L. E. A., F. L., J. S. and I. T. contributed to the development of the study protocol. M. P. and P. R. performed the statistical analysis and informed the study design. E. P. and S. V. developed the manuscript, contributed to the analysis and interpreted the study results.

\section{References}

1. Jequier E \& Constant F (2010) Water as an essential nutrient: the physiological basis of hydration. Eur J Clin Nutr $\mathbf{6 4}$, $115-123$

2. Armstrong LE, Costill DL \& Fink WJ (1985) Influence of diuretic-induced dehydration on competitive running performance. Med Sci Sports Exerc 17, 456-461.

3. Lopez RM, Casa DJ, Jensen KA, et al. (2011) Examining the influence of hydration status on physiological responses and running speed during trail running in the heat with controlled exercise intensity. J Strength Cond Res 25, 2944-2954.

4. Ganio MS, Armstrong LE, Casa DJ, et al. (2011) Mild dehydration impairs cognitive performance and mood of men. Br J Nutr 106, 1535-1543.

5. Smith MF, Newell AJ \& Baker MR (2011) Effect of acute mild dehydration on cognitive-motor performance in golf. $J$ Strength Cond Res (Epublication ahead of print version 20 December 2011).

6. European Food Safety Authority (2011) Scientific opinion on dietary reference values for water. EFSA J 8, 1459-1506.

7. Armstrong LE (2007) Assessing hydration status: the elusive gold standard. J Am Coll Nutr 26, 575S-584S.

8. Kavouras SA (2002) Assessing hydration status. Curr Opin Clin Nutr Metab Care 5, 519-524.

9. Shirreffs SM (2003) Markers of hydration status. Eur J Clin Nutr 57, Suppl. 2, S6-S9.

10. Cheuvront SN, Fraser CG, Kenefick RW, et al. (2011) Reference change values for monitoring dehydration. Clin Chem Lab Med 49, 1033-1037.
11. Casa DJ, Armstrong LE, Hillman SK, et al. (2000) National athletic trainers' association position statement: fluid replacement for athletes. J Athl Train 35, 212-224.

12. Institute of Medicine (2004) Dietary Reference Intakes for Water, Potassium, Sodium, Chloride, and Sulfate. Washington, DC: National Academies Press.

13. TNS-SOFRES (2006) Usage and Attitude Survey. Report commissionned by Danone Eaux France.

14. Bellisle F, Thornton SN, Hebel P, et al. (2010) A study of fluid intake from beverages in a sample of healthy French children, adolescents and adults. Eur J Clin Nutr 64, $350-355$.

15. CIQUAL (2008) Table de composition nutritionnelles des aliments (Food composition table). http://www.ansnes fr/ TableCIQUAL/

16. Armstrong LE, Maresh CM, Castellani JW, et al. (1994) Urinary indices of hydration status. Int J Sport Nutr $\mathbf{4}$, $265-279$.

17. Armstrong LE, Soto JA, Hacker FT, et al. (1998) Urinary indices during dehydration, exercise, and rehydration. Int J Sport Nutr 8, 345-355.

18. Tiselius HG (1991) Aspects on estimation of the risk of calcium oxalate crystallization in urine. Urol Int 47, 255-259.

19. Tack I (2011) Effects of water consumption on kidney function and excretion. Nutr Today 45, S37-S40.

20. Cheuvront SN, Ely BR, Kenefick RW, et al. (2010) Biological variation and diagnostic accuracy of dehydration assessment markers. Am J Clin Nutr 92, 565-573.

21. Francesconi RP, Hubbard RW, Szlyk PC, et al. (1987) Urinary and hematologic indexes of hypohydration. J Appl Physiol 62, 1271-1276.

22. Bouby N \& Fernandes S (2003) Mild dehydration, vasopressin and the kidney: animal and human studies. Eur $J$ Clin Nutr 57, Suppl. 2, S39-S46.

23. Holsboer F \& Ising M (2010) Stress hormone regulation: biological role and translation into therapy. Annu Rev Psychol 61, 81-109.

24. Papadimitriou A \& Priftis KN (2009) Regulation of the hypothalamic-pituitary-adrenal axis. Neuroimmunomodulation 16, 265-271.

25. Francesconi RP, Sawka MN, Pandolf KB, et al. (1985) Plasma hormonal responses at graded hypohydration levels during exercise-heat stress. J Appl Physiol 59, 1855-1860.

26. Maresh CM, Whittlesey MJ, Armstrong LE, et al. (2006) Effect of hydration state on testosterone and cortisol responses to training-intensity exercise in collegiate runners. Int J Sports Med 27, 765-770.

27. Valtin H \& Schafer J (1994) Renal Function, 3rd ed. Boston: Little, Brown and Company.

28. Armstrong LE, Pumerantz AC, Fiala KA, et al. (2010) Human hydration indices: acute and longitudinal reference values. Int J Sport Nutr Exerc Metab 20, 145-153.

29. Clark WF, Sontrop JM, Macnab JJ, et al. (2011) Urine volume and change in estimated GFR in a community-based cohort study. Clin J Am Soc Nephrol 6, 2634-2641.

30. Strippoli GF, Craig JC, Rochtchina E, et al. (2011) Fluid and nutrient intake and risk of chronic kidney disease. Nephrology 16, 326-334.

31. CCAF (2008) Enquête sur les Comportements et Consommations Alimentaires des Français 2003 (Survey on food consumption and Behaviour of the French 2003). In Consommations et comportements alimentaires en France (Food Consumption and Behaviour in France). Paris: Ed. Lavoisier.

32. CCAF (2008) Enquête sur les Comportements et Consommations Alimentaires des Français 2007 (Survey on food con- 
sumption and behaviour of the French 2007). In Consommations et comportements alimentaires en France (Food Consumption and Behaviour in France). Paris: Ed. Lavoisier.

33. Brosnan JT \& Brosnan ME (2007) Creatine: endogenous metabolite, dietary, and therapeutic supplement. Annu Rev Nutr 27, 241-261.

34. Persky AM, Brazeau GA \& Hochhaus G (2003) Pharmacokinetics of the dietary supplement creatine. Clin Pharmacokinet 42, 557-574.

35. Shojaiefard M, Christie DL \& Lang F (2005) Stimulation of the creatine transporter SLC6A8 by the protein kinases SGK1 and SGK3. Biochem Biophys Res Commun 334, 742-746.
36. Waldegger S, Barth P, Raber G, et al. (1997) Cloning and characterization of a putative human serine/threonine protein kinase transcriptionally modified during anisotonic and isotonic alterations of cell volume. Proc Natl Acad Sci US A 94, 4440-4445.

37. Warntges S, Friedrich B, Henke G, et al. (2002) Cerebral localization and regulation of the cell volume-sensitive serum- and glucocorticoid-dependent kinase SGK1. Pflugers Arch 443, 617-624.

38. Tang C, Zelenak C, Volkl J, et al. (2011) Hydrationsensitive gene expression in brain. Cell Physiol Biochem 27, 757-768. 